\title{
Autosomal dominant polycystic kidney disease diagnosed in utero. Review
}

\author{
Magdalena Nowak' ${ }^{1}$, Hubert Huras ${ }^{1}$, Marcin Wiecheć ${ }^{1}$, Robert Jach², \\ Małgorzata Radoń-Pokracka ${ }^{1}$, Joanna Górecka ${ }^{1}$ \\ ${ }^{1}$ Department of Obstetrics and Perinatology, Jagiellonian University Medical College, Krakow, Poland \\ ${ }^{2}$ Department of Gynecological Endocrinology, University Hospital in Krakow, Poland
}

\begin{abstract}
Autosomal dominant polycystic kidney disease (ADPKD) is one of most common inherited renal diseases. It is estimated that very early onset ADPKD affects even $2 \%$ patients. The purpose of this article is to provide a comprehensive review of genetics, prenatal diagnosis and prognosis in very early onset autosomal dominant polycystic kidney disease.

Key words: genetic counseling, congenital malformations, magnetic resonance imaging, prenatal diagnostic, prenatal ultrasonography, autosomal dominant polycystic kidney diseases
\end{abstract}

Ginekologia Polska 2016; 87, 8: 605-608

\section{INTRODUCTION}

Autosomal dominant polycystic kidney disease (ADPKD) is one of the most common hereditary kidney diseases. The incidence rate is estimated at 1/500-1000 live births. Typically, the symptoms develop in the age range from 20 to 50 [1]. It is estimated that an early manifestation of the disease (before 15 years of age) is observed in $2 \%$ of patients [2]. The development of prenatal ultrasound has led to more frequent diagnosis of an intrauterine form of ADPKD [3].

\section{AUTOSOMAL DOMINANT POLYCYSTIC KIDNEY DISEASE}

The clinical picture of ADPKD consists of kidneys enlarged by numerous cysts. These cysts may be present in other organs, such as the liver, the pancreas, a lung, and the arachnoid mater. This congenital disease can be accompanied by other anomalies, such as: intracranial aneurysms, thoracic aortic aneurysms and impaired function of the heart valves. Typically, extreme renal failure develops around 60 years of age $[4,5]$.

\section{GENETICS}

The basis of this disorder is a mutation of PKD-1, PKD-2, or PKD-3 protein-coding polycystine 1 or polycystine 2 . PKD-1 gene is responsible for $85 \%$ of cases of ADPKD and it is located on the short arm of chromosome 16 (16p13.3). PKD-2 gene is located on the long arm of chromosome 4 (4q21), while PKD gene-3 has not been mapped yet $[6,7]$. ADPKD is a disorder inherited in an autosomal dominant fashion. The risk of inheriting this mutation is at the level of $50 \%$. An early onset of this disease is more common when the mother of the child is afflicted by the disease, and when the child is a female $[8,9]$. However, Hammond denies that this disorder has any correlation with gender [10]. The occurrence of early-onset ADPKD significantly increases the risk of recurrence of the disease, with a similar manifestation, in subsequent pregnancies [1].

ADPKD is characterized by heterogeneity of the clinical picture both between families and "within-family". There are many theories explaining such a diversity. One hypothesis explaining this phenomenon is the theory of spontaneous mutations - arising de novo or superimposed on an existing ones, giving new mutations. It is estimated that up to $10 \%$ of patients experience spontaneous mutations. It is believed that early-onset ADPKD is a result of those mutations $[8,11]$. Another theory is associated with the presence of hypomorphic mutation of PKD1 inherited in trans configuration [12-14]. Bergmann notes the relationship of the disease with the mutation of the HNF1B gene [15]. In addition, 
this disease can sometimes be inherited in an autosomal recessive fashion [16].

There are several genetic tests that can be used to detect ADPKD. In most cases, the diagnosis is technically difficult and expensive due to the heterogeneity of gene mutation for polycysteine (a variety of point mutations: nonsense, missense, shifting the reading frame) $[11,17]$. Application of genetic testing may be considered in asymptomatic patients with a family history and for pre-implantation diagnostics.

\section{PRENATAL DIAGNOSIS}

In 2004, Brun et al. described an ultrasound image pattern of kidneys that could suggest ADPKD. Fetal kidneys are slightly increased (1 to $2 \mathrm{SD}$ ), with hyperechogenic cortex and hypoechogenic kidney core, resulting in increased diversity of cortico-spinal fluid. Amniotic fluid index is within the norms. Cysts in the kidneys may be present, but usually they do not appear until after birth [18]. The cases previously reported in the literature show a similar picture of fetal kidneys during an ultrasound examination [4, 8, 19-21]. Figure 1 shows an ultrasound image of fetal kidneys with ADPKD. An ultrasound image showing large, hyperechoic or polycystic kidneys is not characteristic of ADPKD and may be associated with other malformations of the urinary tract (simple renal cyst, cystic renal dysplasia), as well as with other degenerating polycystic kidney disorders (e.g. an autosomal recessive kidney disease ARPKD) or genetic

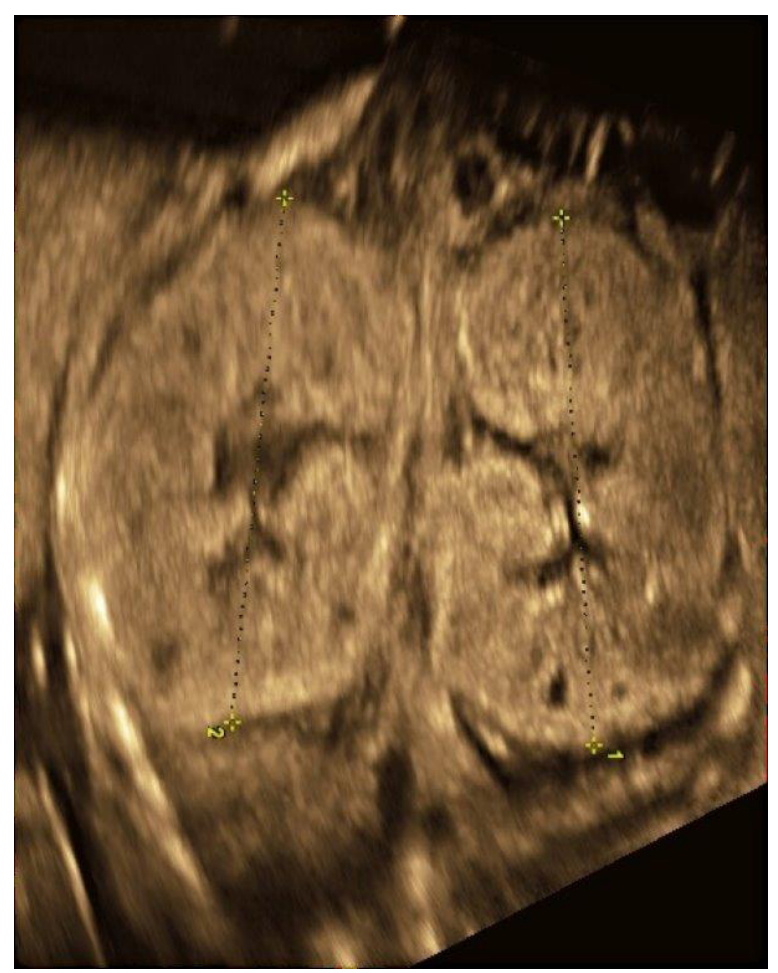

Figure 1. Ultrasound image of fetal kidneys with ADPKD — frontal view

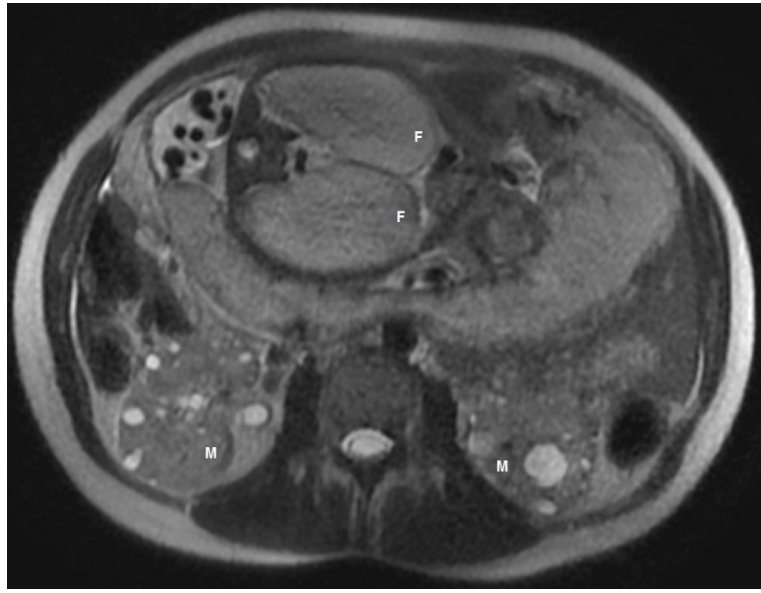

Figure 2. Magnetic resonance image of transvers view of mother kidneys and frontal view of fetal kidneys. Both, mother and fetus had ADPKD; M - mother kidney; F — fetal kidney

syndromes (e.g. Beckwith-Wiedemann syndrome, Jeune syndrome, Lujan-Fryns syndrome, Zellweger syndrome, Trisomy 18). The first step in the differential diagnosis should be the exclusion of other defects of the urinary tract. Subsequently, it is crucial to look for additional anomalies of the fetus. The presence of coexisting anomalies is more characteristic of genetic syndromes, while an isolated kidney disease may be a sign of polycystic kidney disease (PKD) $[9,18]$.

The literature describes cases of fetuses, which were diagnosed in utero with ADPKD based on ultrasound imaging and a positive family history. After birth, these children presented a picture of normal kidneys with proper function [10, 22].

ADPKD symptoms usually do not appear until adulthood and kidney failure progresses subacutely; therefore, up to $60 \%$ of future parents do not know they are affected. Upon diagnosis of the fetus with PKD, parents and even grandparents should be examined for this disorder if there is an absence of a family history [8].

It is particularly important to determine whether ADPKD has been inherited from the mother, since hypertension in pregnant woman with ADPKD is associated with a high risk of feto-maternal complications and require close monitoring and a possible treatment to prevent development of pre-eclampsia [23].

Prenatal magnetic resonance imaging is a complementary diagnostic tool for diagnosis of congenital kidney anomalies [24]. It is a particularly useful analysis in case of oligohydramnios, as an alternative to evaluation of fetal anatomy after diagnostic amnioinfusion [25]. Figure 2 shows maternal and fetal kidneys with ADPKD. Figure 3 present a sagittal view of a fetus with ADPKD.

Using magnetic diffusion resonance (diffusion weighted MR, DW-MR) is also possible to assess the renal function. The DW-MR technique involves the diffusion process (chaotic mo- 


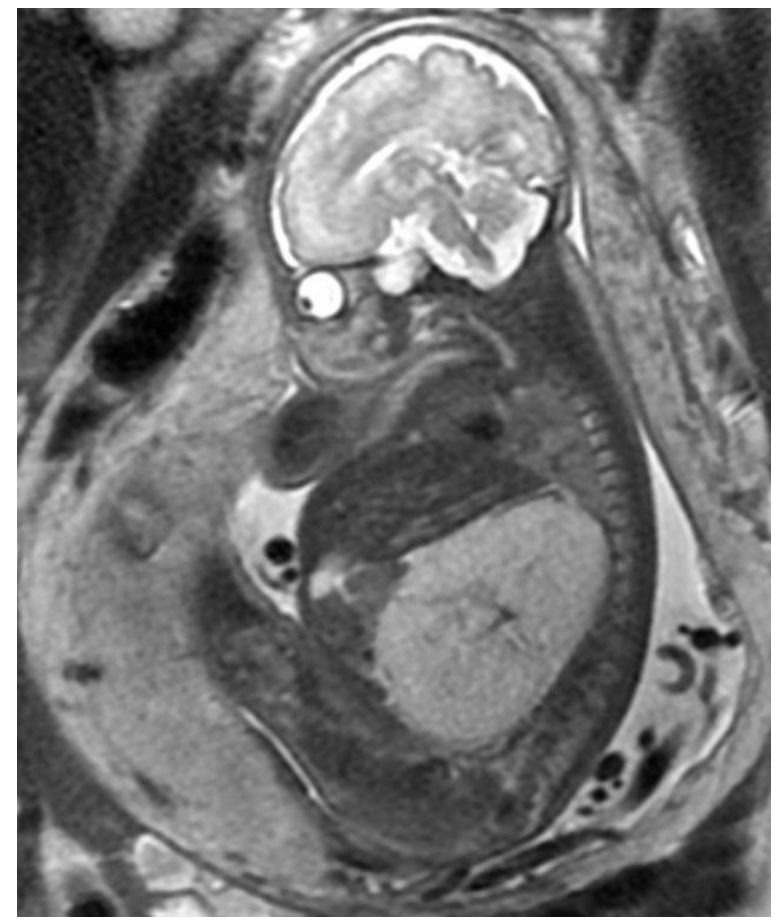

Figure 3. Magnetic resonance image of fetus with ADPKD — sagittal view

tion) of water molecules in tissue. An affected organ will show a hyperintense image due to a failure of the diffusion processes $[26,27]$. Chaumoitre analyzed the results of normal fetuses and of 10 fetuses affected by kidney pathology. In cases of renal polycystic disorders (both ARPKD and ADPKD), as in hydronephrosis, the images gave a hyperintensive signal [28].

\section{PROGNOSIS}

Genetic consultations are very difficult for this group of families, since very little is still known about the observation and progression of renal failure in children diagnosed in utero or showing symptoms of ADPKD in early childhood. The first reports stated that nearly half of all children with ADPKD die before the age of one $[8,29,30]$. However, recent reports have shown favorable prognosis for these children $[31,32]$. Fick et al. described that out of 11 cases diagnosed prenatally: 8 showed a normal or near proper function of the kidneys in the childhood, 2 developed extreme kidney failure, and one fetus was subjected to termination [8]. In 2001, Fick et al. published results of a fifteen-year follow-up of 312 patients whose major problem was drug-resistant hypertension [8,33]. Children with early onset ADPKD often manifest hypertension, albuminuria, and renal failure. Developing albuminuria can be a predictor of disease severity [34].

Oligohydramnios occurring during pregnancy is considered to be a negative prognostic factor. There is no prognostic significance in prenatal ultrasound based on: presence or absence of cysts, their size, number and location [28,
30]. It was shown that the size of the kidney in children as well as in adults correlates with the severity of the disease. Enlarged kidneys in the first decade of life suggest a rapid development of extreme renal failure [35].

\section{SUMMARY}

Autosomal dominant polycystic kidney degeneration (ADPKD) is one of the most common hereditary kidney diseases. It is estimated that an early onset of ADPKD applies up to $2 \%$ of patients. This birth defect is characterized by a wide diversity of clinical symptoms in individual patients. The clinical picture significantly differs not only among families, but also among members of one family. There are currently studies which aim to explain the exact genetic background. The advancement of prenatal ultrasonography led to more frequent diagnosis of intrauterine presentation of this disorder. Large hyperechoic kidneys found in ultrasound picture should lead to a suspicion of this disease. A positive family history and exclusion of other causes enables a proper diagnosis. Sometimes, it is necessary to preform diagnostic testing on parents. Magnetic resonance imaging can be utilized as a complementary diagnostic tool. The survival rate of children suffering from an early onset of ADPKD is relatively high, but they require multiple drug therapies for hypertension at an early age.

\section{REFERENCES}

1. Harris PC, Torres VE. Polycystic kidney disease. Ann Rev Med. 2009, 60, 321-337.

2. Torres VE, Harris PC, Pirson Y. Autosomal dominant polycystic kidney disease. Lancet. 2007, 369, 1287-1301.

3. Sinibaldi $D$, Malena $S$, Mingarelli $R$, [et al.]. Prenatal ultrasonographic findings of dominant polycystic kidney disease and postnatal renal evolution. Am J Med Genet. 1996, 65, 337-341.

4. Friedmann W, Vogel M, Dimer JS, [et al.]. Perinatal differential diagnosis of cystic kidney disease and urinary tract obstruction: anatomic pathologic, ultrasonographic and genetic findings. Eur J Obstet Gynecol Reprod Biol. 2000, 89, 127-133.

5. Bergmann C. ARPKD and early manifestations of ADPKD: the original polycystic kidney disease and phenocopies. Pediatr Nephrol. 2015, 30, 15-30.

6. Hughes J, Ward CJ, Peral B, [et al.]. The polycystic kidney disease 1 (PKD1) gene encodes a novel protein with multiple cell recognition domains. Nat. Genet. 1995, 10, 151-160.

7. Mochizuki T, Wu G, Hayashi T, [et al.]. PKD2, a gene for polycystic kidney disease that encodes an integral membrane protein. Science. 1996, 272, 1339-1342.

8. Fick GM, Johnson AM, Strain JD, [et al.]. Characteristics of very early onset autosomal dominant polycystic kidney disease. J Am Soc Nephrol. 1993, 3, 1863-1870.

9. Chaumoitre K, Brun M, Cassart M, [et al.]. Differential diagnosis of fetal hyperechogenic cystic kidneys unrelated to renal tract anomalies: A multicenter study. Ultrasound Obstet Gynecol. 2006, 28, 911-917.

10. Hammond L, McKenna PH. Spontaneous neonatal regression of prenatally detected renal cysts in autosomal dominant polycystic kidney disease. J Urol. 2004, 171, 331-332.

11. Koptides M, Deltas CC. Autosomal dominant polycystic kidney disease: molecular genetics and molecular pathogenesis. Hum Genet. 2000, 107, 115-126.

12. Rossetti S, Kubly VJ, Consugar MB, [et al.]. Incompletely penetrant PKD1 alleles suggest a role for gene dosage in cyst initiation in polycystic kidney disease. Kidney Int. 2009, 75, 848-855. 
13. Hopp K, Ward CJ, Hommerding CJ, [et al.]. Functional polycystin-1 dosage governs autosomal dominant polycystic kidney disease severity. J Clin Invest. 2012, 122, 4257-4273.

14. Vujic $M$, Heyer $C M$, Ars $E$, [et al.]. Incompletely penetrant PKD1 alleles mimic the renal manifestations of ARPKD. J Am Soc Nephrol. 2010, 21, 1097-1102.

15. Bergmann C, Bothmer J, Ortiz Brüchle N, [et al.]. Mutations in multiple PKD genes may explain early and severe polycystic kidney disease. J Am Soc Nephrol. 2011, 22, 2047-2056.

16. Bergmann C. Ciliopathies. Eur J Pediatr. 2012, 171, 1285-1300.

17. Tan YC, Blumenfeld J, Rennert H. Autosomal dominant polycystic kidney disease: genetics, mutations and microRNAs. Biochim Biophys Acta. 2011, $1812,1202-1212$

18. Brun M, Maugey-Laulom B, Eurin D, [et al.]. Prenatal sonographic patterns in autosomal dominant polycystic kidney disease: a multicenter study. Ultrasound Obstet Gynecol. 2004, 24, 55-61.

19. Sinibaldi $D$, Malena S, Mingarelli $R$, [et al.]. Prenatal ultrasonographic findings of dominant polycystic kidney disease and postnatal renal evolution. Am J Med Genet. 1996, 65, 337-341.

20. Journel H, Guyot C, Barc RM, [et al.]. Unexpected ultrasonographic prenatal diagnosis of autosomal dominant polycystic kidney disease. Prenat Diagn. 1989, 9, 663-671.

21. Michaud J, Russo P, Grignon A, [et al.]. Autosomal dominant polycystic kidney disease in the fetus. Am J Med Genet. 1994, 51, 240-246.

22. Jeffery S, Saggar-Malik AK, Econornides DL, [et al.]. Apparent normalisation of fetal renal size in autosomal dominant polycystic kidney disease [PKDI]. Clin Genet. 1998, 53, 303-307.

23. Chapman AB, Johnson AM, Gabow PA. Pregnancy outcome and its relationship to progression of renal failure in autosomal dominant polycystic kidney disease. J Am Soc Nephrol. 1994, 5, 1178-1185.

24. Abdelazim IA, Belal MM. The role of magnetic resonance imaging in refining the diagnosis of suspected fetal renal anomalies. J Turk Ger Gynecol Assoc. 2013, 14, 6-10.
25. Poutamo J, Vanninen $\mathrm{R}$, Partanen $\mathrm{K}$, [et al.]. Diagnosing fetal urinary tract abnormalities: benefits of MRI compared to ultrasonography. Acta Obstet Gynecol Scand. 2000, 79, 65-71.

26. Thoeny HC, De Keyzer F. Extracranial applications of diffusion-weighted magnetic resonance imaging. Eur Radiol. 2007, 17, 1385-1393.

27. Krawczyk R, Rytlewski J, Poniatowska R, [et al.]. Dyfuzyjne badanie metodą rezonansu magnetycznego-podstawy fizyczne i zastosowania kliniczne. Postępy Psychiatrii i Neurologii. 2005, 14, 47-56.

28. Chaumoitre K, Colavolpe N, Shojai R, [et al.]. Diffusion weighted magnetic resonance imaging with apparent diffusion coefficient (ADC) determination in normal and pathological fetal kidneys. Ultrasound Obstet Gynecol. 2007, 29, 22-31.

29. MacDermot KD, Saggar-Malik AK, Economides DL, [et al.]. Prenata diagnosis of autosomal dominant polycystic kidney disease (PKD 1) presenting in utero and prognosis for very early onset disease. $J$ Med Genet. 1998, 35, 13-16.

30. Winyard P, Chitty L. Dysplastic and polycystic kidneys: diagnosis, associations and management. Prenat Diagn. 2001, 21, 924-935.

31. Boyer O, Gagnadoux MF, Guest G, [et al.]. Prognosis of autosomal dominant polycystic kidney disease diagnosed in utero or at birth. Pediatr Nephrol. 2007, 22, 380-388.

32. Zerres K, Rudnik-Schoneborn S, Deget F. Childhood onset autosomal dominant polycystic kidney disease in sibs: clinical picture and recurrence risk. J Med Genet. 1993, 30, 583-588.

33. Fick-Brosnahan GM, Tran ZV, Johnson AM, [et al.]. Progression of autosomal-dominant polycystic kidney disease in children. Kidney Int. 2001, 59, 1654-1662.

34. Selistre L, de Souza V, Ranchin B, [et al.]. Early renal abnormalities in children with postnatally diagnosed autosomal dominant polycystic kidney disease. Pediatr Nephrol. 2012, 27, 1589-1593.

35. C, Torra R, Bianchi L, [et al.]. Abdominal sonographic study of autosomal dominant polycystic kidney disease. J Clin Ultrasound. 2000, 28, 277-282. 